\title{
Factors Shaping Brand Awareness of Sumba Weaving Products in a Phenomenological Perspective
}

\section{Faktor Pembentuk Brand Awareness Produk Tenun Sumba Dalam Perspektif Fenomenologi}

\author{
Wulan Purnama Sari ${ }^{1}$, Mei Ie ${ }^{2}$, Hetty Karunia Tunjungsari ${ }^{2}$ \\ ${ }^{1}$ Fakultas Ilmu Komunikasi, Universitas Tarumanagara \\ Email: wulanp@fikom.untar.ac.id \\ ${ }^{2}$ Fakultas Ekonomi dan Bisnis, Universitas Tarumanagara \\ Email: meii@fe.untar.ac.id, hetty@fe.untar.ac.id
}

Masuk tanggal : 19-02-2021, revisi tanggal : 29-05-2021, diterima untuk diterbitkan tanggal : 19-07-2021

\begin{abstract}
The fashion industry is included in the top three creative industry sectors in Indonesia. The development of the fashion industry is also supported by various parties and is also enlivened by the distinctive fashion of Indonesian traditional fabrics. Several Indonesian traditional fabrics, such as batik, lurik, Lombok songket have successfully penetrated the international market, so the opportunity to continue developing the fashion industry with traditional fabrics is still wide open. One of the ways is to use a typical Sumba woven fabric which is not gaining popularity with Sumba as a tourist destination. Therefore, this research was conducted with the aim of digging deeper into the factors that shape the brand awareness of Sumba woven fabrics. This research is conducted using a qualitative approach and phenomenological methods, with data collection using the Focus Group Discussion (FGD) technique. The results show that the factors which formed brand awareness of Sumba woven fabrics were divided into two, namely internal and external factors. Internal factors are factors that come from the product itself, such as motif, price, color, age of fabric, quality, craftsmen. While external factors come from outside the product, including the power of word of mouth, organizing events (exhibitions), government involvement (regional and central), and showing the identity of the wearer.
\end{abstract}

Keywords: brand awareness, creative industry, Sumba Woven Fabric

\begin{abstract}
Abstrak
Industri fashion termasuk dalam tiga besar sektor industri kreatif di Indonesia. Perkembangan industri fashion ini juga didukung berbagai pihak, serta turut diramaikan dengan fashion khas kain tradisional Indonesia. Beberapa kain tradisional Indonesia, seperti batik, lurik, songket Lombok telah berhasil menembus pasar internasional, sehingga peluang untuk terus mengembangkan industri fashion dengan kain tradisional masih besar. Salah satunya adalah dengan menggunakan kain tenun khas Sumba yang kurang mendapatkan popularitas dengan Sumba
\end{abstract}


sebagai destinasi wisata. Oleh karenanya, penelitian ini dilakukan dengan tujuan untuk menggali lebih dalam mengenai faktor yang membentuk brand awareness kain tenun Sumba. Penelitian menggunakan pendekatan kualitatif dengan metode fenomenologi, teknik pengumpulan data berupa Focus Group Discussion (FGD). Hasil penelitian menunjukkan bahwa faktor yang membentuk brand awareness atas produk kain tenun Sumba dibedakan menjadi dua, yaitu faktor internal dan eksternal. Faktor internal merupakan faktor yang berasal dari produk sendiri, seperti motif, harga, warna, usia kain, kualitas, pengrajin, sedangkan faktor eskternal berasal dari luar produk, meliputi kekuatan dari word of mouth, penyelenggaraan event (pameran), keterlibatan pemerintah (daerah dan pusat), dan menunjukkan identitas pemakainya.

Kata Kunci: brand awareness, industri kreatif, kain tenun Sumba

\section{Pendahuluan}

Berdasarkan hasil survei yang dilakukan oleh Bekraf (Badan Ekonomi Kreatif) dan BPS (Badan Pusat Statistik) pada tahun 2016 kemarin, ekonomi kreatif Indonesia dikuasai oleh tiga sektor, yaitu kuliner; fashion; dan kriya. Kuliner memberikan kontribusi sebesar $41,40 \%$; sektor fashion memberikan kontribusi sebesar $18,01 \%$; sektor kriya berkontribusi sebesar $15,40 \%$ dan $25,19 \%$ sisanya dari sector lain (Data Statistik Dan Hasil Survei Ekonomi Kreatif 2016, 2019). Data tersebut menunjukkan bahwa peluang di industri fashion masih terbuka dan luas. Perkembangan industri fashion ini juga didukung berbagai pihak, misalnya dengan diselenggarakannya Indonesia Fashion Week dan juga dibentuknya forum mode khusus Indonesia, yang bernama Indonesia Fashion Forward. Upaya yang menjadikan desainer Indonesia sebagai tuan rumah di tempat sendiri, meningkatkan kewiraswastaan industri fashion ("Gairah Fashion Indonesia Di Panggung Dunia," 2017). Sebagai industri kreatif, fashion di Indonesia juga diwarnai dengan penggunaan kain tradisional khas Indonesia sebagai bahan dasar fashion. Kain tradisonal tersebut menunjukkan nilai budaya dalam industri fashion, dan bahkan diminati oleh pasar Internasional, sehingga peluang bisnis fashion untuk kain tradisionalnya masih cukup besar.

Beberapa jenis kain tradisional Indonesia telah mendunia, seperti batik, lurik, songket Lombok, ulos Batak, tenun Dayak, tapis Lampung, jumputan, dsb ("10 Kain Tradisional Khas Indonesia Yang Mendunia," 2019; 13 Kain Tradisional Khas Indonesia Yang Luar Biasa Indah, Sudah Punya?, 2019). Berbicara tentang kain tradisional sendiri, setiap daerah di Indonesia memiliki ciri khas masingmasing dan belum semua dikenal dengan baik oleh masyarakat Indonesia sendiri. Sebagai contohnya adalah kain tenun khas Sumba yang kurang mendapatkan popularitas bila dibandingkan dengan lurik, ulos, tenun Dayak, dll yang telah mendunia. Hal ini berbanding terbalik dengan popularitas Sumba sendiri sebagai destinasi wisata, yang juga telah mendunia.

Penelitian pendahuluan yang dilakukan pada bulan Januari 2020 menunjukkan bahwa hanya $20 \%$ responden (dari 30 orang responden) menyebutkan Sumba sebagai salah satu daerah penghasil tenun di Indonesia. Mayoritas 
responden menyebutkan ulos Batak, songket Lombok dan lurik Jawa sebagai tenun khas Indonesia. maka dapat ditarik sebuah asumsi awal bahwa kain tenun Sumba belum memiliki brand awareness yang cukup bila dibandingkan dengan kain tradisional lainnya yang dimiliki oleh Indonesia. Penelitian awal juga dilakukan untuk mendapatkan informasi terkini mengenai bisnis tenun Sumba yang dijalankan oleh pengrajin di Sumba. Berdasarkan hasil wawancara dengan narasumber di Sumba Barat diperoleh data bahwa selama ini pengrajin tenun Sumba relatif mengalami kesulitan dalam memasarkan produknya. Beberapa kendala yang mereka hadapi antara lain adalah kurangnya kemampuan dalam memasarkan produk serta tidak adanya akses ke pasar di luar daerah mereka. Pembeli tenun Sumba rata-rata adalah turis yang mengunjungi Sumba Barat dan membeli dengan tujuan mendapatkan cindera mata.

Tenun Sumba memiliki potensi yang cukup besar untuk menjadi produk unggulan fashion khas Indonesia dan dapat mengangkat citra Sumba sebagai destinasi wisata secara luas. Oleh sebab itu, penelitian ini dilakukan dengan tujuan untuk mengetahui faktor-faktor yang mampu membentuk brand awareness atas produk kain tenun Sumba, dengan mengetahui faktor-faktor tersebut, diharapkan dapat bermanfaat bagi para pengrajin tenun Sumba untuk mengembangkan produknya dalam hal pemasaran dan komunikasi pemasaran.

Penelitian terkait dengan konsep pengembangan brand secara luas telah banyak dilakukan. Sebagai contoh, beberapa penelitian yang pernah dilakukan oleh Valaei \& Nikhashemi (2017) yang meneliti terkait merek dan identitas konsumen adalah faktor yang paling membentuk sikap konsumen Gen-Y terhadap produk fashion. Selain itu, merek, gaya, harga, dan identitas sosial adalah faktor paling berpengaruh dari niat pembelian konsumen Gen-Y untuk produk fashion. Penelitian mereka juga menemukan bahwa gaya, harga, negara asal, dan identitas sosial tidak relevan dengan sikap konsumen Gen-Y terhadap produk fashion. Terdapat pula penelitian yang dilakukan untuk mengetahui minat konsumen pada produk fashion dengan konsep eco friendly (Gam, 2011). Dalam konteks pembelian produk fashion secara online, Kautish \& Sharma (2018) menunjukkan bahwa nilai-nilai instrumental dan terminal secara signifikan memengaruhi kesadaran mode, dan kesadaran mode memiliki dampak yang signifikan terhadap niat perilaku juga.

Sementara penelitian lainnya menyatakan bahwa salah satu faktor pendorong perilaku konsumen terhadap pembelian produk fashion adalah dominasi dari interaksi sosial. Pembelian produk fashion seringkali tidak hanya tergantung pada persepsi konsumen yang bersangkutan, namun seringkali juga dipengaruhi oleh respon orang-orang di sekitarnya. Produk fashion seringkali mencerminkan gaya hidup konsumen tersebut dan juga sebagai cara konsumen tersebut menunjukkan kepribadiannya. Oleh karena itu, produk fashion yang tersedia harus dapat memenuhi kebutuhan dan keinginan konsumen agar produk tersebut dapat menimbulkan minat beli bagi calon konsumennya. (Rajagopal, 2011)

Penelitian terkait pengukuran brand awareness untuk destinasi wisata juga pernah dilakukan. Penelitian ini dilakukan untuk mengukur tingkat destination awareness wisatawan lokal terhadap objek wisata Candi Muaro Jambi. Penelitian dengan menggunakan metode survei. Hasil penelitian ini memberikan kontribusi ilmiah terkait dengan bidang pemasaran destinasi, khususnya terkait dengan 
destination awareness suatu destinasi wisata domestik. Secara praktis, hasil penelitian ini dapat menjadi dasar pembentukan kebijakan pemasaran destinasi yang bertujuan untuk meningkatkan awareness wisatawan domestik terhadap berbagai destinasi wisata yang ada di Indonesia. (Tunjungsari et al., 2019)

Penelitian lain terkait pengukuran brand awareness juga dilakukan terhadap produk sepatu olahraga dalam kaitannya dengan promosi dan purchase intention melalui media sosial. Sampel penelitian 100 responden masyarakat Surabaya yang telah melihat promosi di media sosial sepatu olahraga Specs. Hasil penelitian menunjukkan: (1) Promosi berpengaruh positif terhadap brand awareness produk sepatu olahraga yang digunakan; (2) Brand awareness berpengaruh positif terhadap purchase intention; (3) promosi berpengaruh positif terhadap purchase intention. Brand awareness dapat menjadi mediasi antara promosi dan purchase intention. (Semuel \& Setiawan, 2018).

Beberapa contoh penelitian terdahulu di atas menunjukkan bahwa penelitian terkait pengukuran brand awareness dapat dilakukan terhadap berbagai objek dan sudut pandang konseptual yang berbeda pula. Penelitian ini sendiri dilakukan untuk menggali faktor yang membentuk brand awareness kain tenun Sumba sebagai salah satu komoditi yang dapat dikembangkan menjadi produk pariwisata dan juga bagian dari ekonomi kreatif. Kajian mengenai brand awareness berkaitan dengan komunikasi pemasaran, karena kemampuan konsumen untuk dapat mengidentifikasikan suatu merek memiliki hubungan dengan teknik komunikasi yang digunakan suatu merek dalam melakukan pemasaran. Teknik komunikasi yang digunakan dalam kegiatan pemasaran merupakan bagian dari komunikasi pemasaran yang dapat dilakukan melalui berbagai saluran, sedangkan kemampuan konsumen untuk dapat mengidentifikasi suatu merek merupakan bagian dari brand awareness. Tingkatan brand awareness yang dapat diperoleh oleh suatu merek bergantung pada kegiatan komunikasi pemasaran yang dilakukan. Oleh karenanya, penelitian mengkaji brand awareness dari sisi komunikasi pemasaran. Pada bagian berikutnya dijelaskan mengenai konsep yang digunakan dalam peneliitian ini, yaitu brand awareness dan komunikasi pemasaran.

\section{Brand Awareness}

Brand awareness didefinisikan sebagai kemampuan konsumen untuk mengidentifikasikan suatu merek dengan cukup detail dalam melakukan suatu pembelian (Rossiter, 2014). Brand awareness berpengaruh positif terhadap minat beli (Hutter et al., 2013; Schivinski \& Dabrowski, 2013; Yaseen \& Mazahir, 2019). Brand awareness membuat konsumen merasa familiar (mengenal) suatu merek, sehingga hal tersebut dapat menciptakan bahkan meningkatkan minat beli terhadap suatu merek. Konsumen juga cenderung akan lebih meningkatkan pembelian terhadap merek yang lebih mereka kenal (Kamins \& Marks, 1991; dalam Yaseen \& Mazahir, 2019).

Radder and Huang (2008; dalam Yaseen \& Mazahir, 2019) menyatakan pentingnya brand awareness dalam memengaruhi minat beli di dalam pasar dengan tingkat persaingan yang tinggi. Brand awareness akan membangun kesukaan terhadap suatu merek yang pada akhirnya mengarahkan konsumen untuk melakukan pembelian produk pada merek tersebut (Ross \& Harradine, 2004). 
Brand Awareness memiliki peranan penting dalam proses pengambilan keputusan pembelian oleh konsumen dan memiliki kontrol atas evaluasi resiko yang dirasakan oleh konsumen terhadap keputusan pembelian tersebut, dengan kata lain konsumen melakukan pembelian atas dasar adanya kesadaran atas suatu merek tersebut beserta dengan keunikan yang dimilikinya dan keyakinan atas merek tersebut. (Ehsan Malik et al., 2013)

Kotler dan Keller (2016) mengemukakan sebuah model untuk pengukuran brand awareness, yaitu AIDA, perhatian (attention), minat (interest), keinginan (desire), atau tindakan (action). Attention, tahap awal dalam menilai suatu produk atau jasa sesuai dengan kebutuhan calon pelanggan, selain itu calon pelanggan juga mempelajari produk atau jasa yang ditawarkan. Interest, pada tahap ini calon pelanggan mulai tertarik untuk membeli produk atau jasa yang ditawarkan, setelah mendapatkan informasi yang lebih terperinci mengenai produk atau jasa yang ditawarkan. Desire, dalam tahap ini calon pelanggan sudah mulai berminat terhadap produk atau jasa yang ditawarkan, ditandai dengan munculnya minat yang kuat dari calon pelanggan untuk membeli dan mencoba produk atau jasa tersebut. Action, pada tahap ini calon pelanggan telah mempunyai kemantapan yang tinggi untuk membeli atau menggunakan produk atau jasa yang ditawarkan.

\section{Komunikasi Pemasaran}

Komunikasi pemasaran diartikan sebagai kegiatan pemasaran yang menggunakan teknik - teknik komunikasi yang berfungsi memberi informasi kepada orang banyak agar tujuan perusahaan tercapai dan terjadi peningkatan pendapatan atas penggunaan jasa atau pembelian produk yang ditawarkan. Kegiatan komunikasi pemasaran perlu dilakukan untuk mendukung diferensiasi dibandingkan dengan pesaing. Kegiatan komunikasi pemasaran ini dapat dilakukan melalui berbagai saluran media dengan harapan terjadinya perubahan dalam hal pengetahuan, sikap, dan Tindakan. (Kusniadji, 2018; Octavia \& Sari, 2019)

Komunikasi pemasaran dapat dilakukan melalui berbagai saluran, yaitu: advertising, sales promotion, public relations, personal selling, dan direct marketing (Kotler \& Keller, 2016). Pemilihan dari saluran komunikasi pemasaran ini harus dapat menyesuaikan dengan kemampuan dan tujuan yang ingin dicapai. Upaya terkoordinasi dalam melakukan kegiatan komunikasi pemasaran melalui berbagai saluran, disebut juga dengan komunikasi pemasaran terpadu (Jasinta \& Oktavianti, 2019).

\section{Metode Penelitian}

Penelitian dilakukan dengan menggunakan pendekatan kualitatif, khususnya dengan menggunakan metode fenomenologi. Studi fenomenologi menggambarkan makna dari beberapa individu mengenai pengalaman hidup mereka atas suatu konsep atau sebuah fenomena. Studi ini berfokus pada cara menggambarkan seluruh kesamaan yang partisipan miliki ketika mereka mengalami atau merasakan sebuah fenomena. Tujuan dasar dari studi fenomenologi ini adalah untuk mengurangi pengalaman individu atas sebuah fenomena menjadi sebuah deskripsi esensi umum yang dimiliki bersama atau secara universal. Pada 
studi ini, peneliti mengidentifikasi fenomena (pengalaman manusia), kemudian melakukan pengumpulan data dari orang yang pernah mengalami fenomena tersebut dan mengembangkan sebuah deskripsi mengenai inti dari setiap pengalaman bagi seluruh partisipan. Deskripsi ini terdiri dari "apa" yang mereka alami dan "bagaimana" mereka mengalaminya. (Creswell, 2014)

Fenomenologi dalam penelitian ini dilakukan untuk memberikan pemahaman atau deskripsi mendalam dari pengalaman setiap partisipan terkait brand awareness atas produk kain tenun Sumba, sehingga dapat ditarik sebuah esensi mengenai tingkat kesadaran konsumen secara umum atas produk kain tenun Sumba sebagai sebuah komoditas.

Berikut akan dijelaskan mengenai objek dan subjek dalam penelitian ini. Objek penelitian ini adalah pengalaman partisipan terkait keberadaan kain tradisonal, khususnya kain tenun Sumba, pengalaman ini dapat diterjemahkan dalam bentuk makna, serta sikap atau prilaku atas kain tenun Sumba. Sedangkan subjek penelitian ini adalah individu yang merupakan kolektor, penggiat, maupun konsumen loyal produk fashion dengan kain khas tradisional Indonesia, khususnya kain tenun Sumba. Berdasarkan subjek dan objek penelitian tersebut kemudian, kriteria untuk penentuan partisipan adalah sebagai berikut: (1) memiliki produk fashion dari kain tradisional khas Indonesia dari Sumba; (2) merupakan penggiat maupun kolektor/pencinta dari kain tradisional khas Indonesia, terutama dari Sumba; (3) memiliki kesadaran untuk memakai produk khas Indonesia. Teknik pemilihan partisipan menggunakan teknik snow ball sampling, dengan total partisipan berjumlah 10 orang dengan beragam latar belakang dan profesi, mulai dari akademisi, profesional, dan kolektor kain tradisional Indonesia.

Data dalam penelitian ini diperoleh melalui teknik Focus Group Discussion (FGD), yaitu suatu diskusi yang dilakukan secara sistematis serta terarah mengenai suatu isu atau masalah tertentu. Selain FGD, data juga diperoleh melalui studi litelatur. Teknik analisis data dalam penelitian ini menggunakan teknik dari Miles and Huberman, yang mencakup reduksi data, penyajian data, dan kesimpulan atau verifikasi (Sugiyono, 2013). Reduksi data dilakukan dengan menajamkan, menggolongkan, mengarahkan, membuang yang tidak perlu dan mengorganisasi data sedemikian rupa. Penyajian data dilakukan dengan menyusun data yang telah dirangkum ke dalam bentuk teks naratif, grafik, jaringan dan began, sedangkan penarikan kesimpulan adalah hasil analisis yang dapat digunakan untuk mengambil tindakan.

\section{Hasil Penemuan dan Diskusi}

Penelitian ini dilakukan atas dasar adanya temuan awal bahwa kain tenun Sumba kurang populer dibandingkan dengan kain tradisonal lainnya, seperti, Ulos Batak, Lurik Jawa, Songket Lombok. Kemudian hasil penelitian awal juga menunjukkan bahwa dari sisi pengrajin kain tenun Sumba juga memiliki kesulitan dalam memasarkan produknya. Oleh karenanya penelitian ini kemudian dilakukan dengan tujuan untuk menggali lebih dalam mengenai faktor yang membentuk brand awareness kain tenun Sumba. Data yang diperoleh melalui FGD kemudian 
Wulan Purnama Sari, Mei Ie, Hetty Karunia Tunjungsari:

Factors Shaping Brand Awareness of Sumba Weaving Products in a Phenomenological Perspective Faktor Pembentuk Brand Awareness Produk Tenun Sumba Dalam Perspektif Fenomenologi

dianalisis dan diolah. Berikut adalah tabel data hasil FGD yang dilakukan dengan kesepuluh partisipan dalam penelitian ini.

Tabel 1. Data Hasil FGD

\begin{tabular}{|c|c|c|}
\hline No. & ertanyaan & Hasil \\
\hline 1 & $\begin{array}{l}\text { Faktor-faktor apa sajakah yang } \\
\text { menentukan pembelian atas produk } \\
\text { kain tradisional? }\end{array}$ & $\begin{array}{ll}- & \text { Motif (uniqueness, warna, karakter) } \\
- & \text { Harga, bahan baku, usia kain } \\
- & \text { Word of mouth (pembelian atas } \\
& \text { adanya rekomendasi dari orang lain) }\end{array}$ \\
\hline 2 & $\begin{array}{l}\text { Apakah merek kain tradisional } \\
\text { penting? }\end{array}$ & $\begin{array}{l}\text { Merek kurang penting, yang utama adalah } \\
\text { kualitas dan siapa pengrajinnya. }\end{array}$ \\
\hline 3 & $\begin{array}{l}\text { Apakah anda } \\
\text { khusus untuk } \\
\text { tradisional? }\end{array}$ & $\begin{array}{l}\text { - Tidak ada budget khusus setiap } \\
\text { bulannya, pembelian didasarkan pada } \\
\text { event } \\
\text { - Khusus untuk kolektor kain } \\
\text { tradisional setiap bulan pasti ada } \\
\text { pembelian }\end{array}$ \\
\hline 4 & $\begin{array}{l}\text { Seberapa penting kain tradisional } \\
\text { dalam mendukung kegiatan anda di } \\
\text { pekerjaan? }\end{array}$ & $\begin{array}{l}\text { Untuk seragam di acara tertentu saja } \\
\text { Bentuk komodifikasi dari fashion. }\end{array}$ \\
\hline 5 & $\begin{array}{l}\text { Seberapa penting kain tradisional } \\
\text { dalam mendukung kegiatan anda } \\
\text { bersosialisasi di masyarakat? }\end{array}$ & Menunjukka \\
\hline 6 & $\begin{array}{l}\text { Apakah anda menggunakan kain } \\
\text { tradisional agar dapat tampil } \\
\text { berbeda dibanding masyarakat } \\
\text { secara umum? }\end{array}$ & Tidak. \\
\hline 7 & $\begin{array}{l}\text { Apakah kain tradisional dapat } \\
\text { menciptakan image khusus bagi } \\
\text { penggunanya? }\end{array}$ & Tidak. \\
\hline 8 & $\begin{array}{l}\text { Apakah harga kain tradisional relatif } \\
\text { lebih mahal dibanding produk } \\
\text { fashion lainnya? }\end{array}$ & $\begin{array}{l}\text { Relatif, bergantung pada perspektif setiap } \\
\text { individu }\end{array}$ \\
\hline 9 & $\begin{array}{l}\text { Dimanakah sebaiknya } \\
\text { tradisional dipasarkan? }\end{array}$ & $\begin{array}{l}\text { Toko dalam bentuk konvensional maupun } \\
\text { online }\end{array}$ \\
\hline 10 & $\begin{array}{lrr}\text { Apa masukan anda } & \text { untuk } \\
\text { meningkatkan kualitas } & \text { kain } \\
\text { tradisional indonesia? } & \\
\end{array}$ & $\begin{array}{l}\text { Quality control, pembuatan infografis, } \\
\text { keterlibatan pemerintah, pemanfaatan } \\
\text { inovasi teknologi }\end{array}$ \\
\hline
\end{tabular}

Berdasarkan tabel di atas dapat ditarik beberapa poin penting mengenai faktor yang menjadi pembentuk brand awareness dari kain tenun Sumba. Pertama, faktor yang berasal dari produknya sendiri (motif, harga, warna, usia kain, kualitas, pengrajin). Kedua, faktor yang berasal dari luar produk, kekuatan dari word of mouth, penyelenggaraan event (pameran), keterlibatan pemerintah (daerah dan pusat), dan menunjukkan identitas pemakainya.

Pembentukan brand awareness terhadap kain tenun Sumba dari faktor eksternal dapat memanfaatkan kekuatan dari word of mouth (WOM), telah banyak penelitian dan kajian yang dilakukan yang menunjukkan bahwa word of mouth 
memiliki efek besar dalam kegiatan pemasaran (Ajorlou et al., 2018; Cheema \& Kaikati, 2010; Jalilvand \& Samiei, 2012; Wang, 2011). Efek WOM ini juga dapat dimanfaatkan dalam penggunaan teknologi komunikasi online, yang berpengaruh pada minat pembelian dan brand image. Pemanfaatan WOM harus memperhatikan informasi yang disebarkan, informasi harus bersifat rekomendasi positif, keunikkan dari produk, detail produk, dan konsistensi informasi yang disebarkan, jika tidak efek yang dihasilkan akan berdampak pada brand image yang negatif dan akhirnya penurunan terhadap minat pembelian. Berdasarkan hal tersebut, WOM memiliki peran penting dalam proses pemasaran suatu produk termasuk di dalamnya pembentukan brand awareness. Komunikasi WOM yang dikelola dengan baik akan memberikan pengaruh yang positif juga pada brand awareness, penerimaan atas produk, dan akhirnya keputusan pembelian atas suatu produk (Rachman \& Abadi, 2017). Kegiatan komunikasi pemasaran melalui WOM juga merupakan bagian dari komunikasi pemasaran terpadu, dimana kegiatan komunikasi pemasaran dapat dilakukan melalui banyak saluran dan salah satunya adalah WOM.

Upaya pemanfaatan WOM ini juga harus mendapat dukungan dari pemerintah, baik pemerintah daerah maupun pusat. Produk kain tenun Sumba merupakan produk dari budaya yang dimiliki Indonesia, yang dapat menunjukkan identitas budaya di Indonesia. Corak dan warna pada kain tradisional memiliki makna dan menjadi simbol tersendiri bagi suatu budaya (Leuape \& Dida, 2017), tidak terkecuali dalam hal kain tenun Sumba. Upaya pemerintah dapat diwujudkan dengan berbagai cara, misalnya penyelenggarakan kegiatan pameran, dan juga kampanye untuk meningkatkan kesadaran masyarakat Indonesia untuk bangga memakai kain trandisional, dukungan dalam bentuk pengembangan sarana dan prasarana, sehingga dengan kata lain dukungan dari pemerintah menjadi penunjang dari kegiatan komunikasi pemasaran terpadu, yang pada akhirnya dapat semakin meningkatkan brand awareness.

Selain, pemanfaatan WOM dan peran pemerintah, melalui penelitian ini juga diperoleh masukan lain yang dapat dimanfaatkan untuk meningkatkan kesadaran masyarakat mengenai kain tenun Sumba, melalui upaya sebagai berikut: (1) Melakukan quality control atas produk, hal ini diperlukan terkait faktor internal misalnya kualitas bahan, warna, ukuran, dan harga; (2) Pembuatan infografis, infografis ini utamanya ditujukan untuk wisatawan baik domestik maupun mancanegara, infografis dapat berisi peta lokasi desa pengrajin, pusat produk kain tenun dipasarkan, motif khas dari kain tenun, dan rentang harga; (3) Melakukan kerjasama yang melibatkan pemerintah, termasuk di dalamnya adalah penyelenggaraan pameran seperti INACRAFT, informasi terkait produk dalam situs resmi pemerintah; (4) memanfaatkan penggunaan inovasi teknologi, dengan adanya internet dan media sosial dapat dimanfaatkan sebagai sarana pemasaran lintas negara dan lintas generasi.

Temuan lain dari penelitian ini adalah adanya kekhawatiran bahwa makna atau nilai dari kain tenun Sumba akan hilang atau memudar pada generasi muda. Generasi muda hanya memahami kain tradisional sebagai bagian dari fashion, kain tradisional telah menjadi produk komodifikasi objek dagang tanpa memperhatikan pelestarian dari makna dan nilai yang terkandung di dalamnya. Kondisi kapitalisme global juga menjadi salah satu faktor pendorong memudarnya makna budaya, 
dimana produk budaya diubah sedemikian rupa hanya untuk kepentingan kelompok yang memiliki kekuatan/kapitalis (Santoso et al., 2015; Sukarwo, 2017; Syafaruddin \& Mahfiroh, 2020).

Masukan sebagai hasil dari penelitian juga perlu dilakukan literasi dan sosialisasi atas nilai dan makna dari kain tradisional pada generasi muda, hal ini dapat dilakukan dengan menggunakan media sosial yang dekat dengan generasi muda (Velasquez \& LaRose, 2015; Yusop \& Sumari, 2013). Media sosial juga dapat dimanfaatkan sebagai sarana pemasaran baru untuk menarik minat pembelian generasi muda (Schivinski \& Dabrowski, 2013; Valaei \& Nikhashemi, 2017).

\section{Simpulan}

Faktor yang mendorong pembentukkan brand awareness atas produk kain tenun Sumba dibedakan menjadi dua, yaitu faktor internal dan eksternal. Faktor internal merupakan faktor yang berasal dari produk sendiri, seperti motif, harga, warna, usia kain, kualitas, pengarajin. Faktor eskternal berasal dari luar produk, meliputi kekuatan dari word of mouth, penyelenggaraan event (pameran), keterlibatan pemerintah (daerah dan pusat), dan menunjukkan identitas pemakainya.

Upaya untuk meningkatkan kesadaran terhadap kain tenun Sumba dapat dilakukan melalui beberapa cara, yaitu: (1) Melakukan quality control atas produk; (2) Pembuatan infografis; (3) Melakukan kerjasama yang melibatkan pemerintah; (4) memanfaatkan penggunaan inovasi teknologi.

Berdasarkan kesimpulan di atas, saran yang dapat berikan dari adanya penelitian ini adalah sebagai berikut: (1) Melakukan penelitian lanjutan mengenai karakteristik dari wisatawan yang datang ke Sumba, sehingga dapat diidentifikasi cara pemasaran yang tepat pada sasaran; (2) Kegiatan PKM dapat dilakukan untuk membantu pengembangan pengrajin kain tenun dalam memasarkan produknya, misalnya pembuatan situs mengenai desa pengrajin serta produk yang mereka hasilnya, dan sosialisasi penggunaan situs ecommerce, literasi nilai dan makna kain tradisional pada generasi muda.

\section{Ucapan Terima Kasih}

Peneliti mengucapkan terima kasih kepada seluruh narasumber yang telah bersedia berpartisipasi dalam penelitian ini. Ucapan terima kasih juga diberikan kepada Pusat Studi Kewirausahaan dan LPPM Untar.

\section{Daftar Pustaka}

10 Kain Tradisional Khas Indonesia yang Mendunia. (2019, March 24). Sindo. https://lifestyle.sindonews.com/read/1388542/186/10-kain-tradisionalkhas-indonesia-yang-mendunia-1553089920

13 Kain Tradisional Khas Indonesia yang Luar Biasa Indah, Sudah Punya? (2019). IDN Times. https://www.idntimes.com/travel/destination/fafa/13-kaintradisional-khas-indonesia-yang-luar-biasa-indah 
Ajorlou, A., Jadbabaie, A., \& Kakhbodc, A. (2018). Dynamic Pricing in Social Networks: The Word-of-Mouth Effect. Management Science, 64(2), 971979. https://doi.org/10.1287/mnsc.2016.2657

Cheema, A., \& Kaikati, A. M. (2010). The Effect of Need for Uniqueness on Word of Mouth. Journal of Marketing Research, 47(3), 553-563. https://doi.org/10.1509/jmkr.47.3.553

Creswell, J. W. (2014). Research Design: Qualitative, Quantitative, and Mixed Methods Approaches (4th ed.). Sage Publication, Inc.

Data Statistik dan Hasil Survei Ekonomi Kreatif 2016. (2019). https://www.bekraf.go.id/pustaka/page/data-statistik-dan-hasil-surveiekonomi-kreatif-2016

Ehsan Malik, M., Mudasar Ghafoor, M., Kashif Iqbal, H., Riaz, U., ul Hassan, N., Mustafa, M., \& Shahbaz, S. (2013). Importance of Brand Awareness and Brand Loyalty in assessing Purchase Intentions of Consumer. International Journal of Business and Social Science, 4(5), 167-171. www.ijbssnet.com

Gairah Fashion Indonesia di Panggung Dunia. (2017, December). Retas. https://www.bekraf.go.id/berita/page/17/gairah-fashion-indonesia-dipanggung-dunia-retas-vol-6-desember-2017

Gam, H. J. (2011). Are fashion-conscious consumers more likely to adopt ecofriendly clothing? Journal of Fashion Marketing and Management, 15(2), 178-193. https://doi.org/10.1108/13612021111132627

Hutter, K., Hautz, J., Dennhardt, S., \& Füller, J. (2013). The impact of user interactions in social media on brand awareness and purchase intention: The case of MINI on Facebook. Journal of Product and Brand Management, 22(5), 342-351. https://doi.org/10.1108/JPBM-05-2013-0299

Jalilvand, M. R., \& Samiei, N. (2012). The Effect of Electronic Word of Mouth on Brand Image and Purchase Intention: an Empirical Study in The Automobile Industry in Iran. Marketing Intelligence and Planning, 30(4), 460-476. https://doi.org/10.1108/02634501211231946

Jasinta, F. A., \& Oktavianti, R. (2019). Strategi Komunikasi Pemasaran Terpadu dalam Pengambilan Keputusan Konsumen di Bidang Jasa Pendidikan. Prologia, 3(2), 423-432. https://doi.org/10.24912/pr.v3i2.6381

Kautish, P., \& Sharma, R. (2018). Consumer values, fashion consciousness and behavioural intentions in the online fashion retail sector. International Journal of Retail and Distribution Management, 46(10), 894-914. https://doi.org/10.1108/IJRDM-03-2018-0060

Kotler, P., \& Keller, K. L. (2016). Marketing Mangement. In Pearson Edition Limited.

Kusniadji, S. (2018). Kontribusi Penggunaan Personal Selling Dalam Kegiatan Komunikasi Pemasaran Pada Era Pemasaran Masa Kini. Jurnal Komunikasi, 9(2), 176-183. https://doi.org/10.24912/jk.v9i2.1078

Leuape, E. S., \& Dida, S. (2017). Dialetika Etnografi Komunikasi Emik-Etik Pada Kain Tenun . Jurnal Kajian Komunikasi, 5(2), 147. https://doi.org/10.24198/jkk.v5i2.8637

Octavia, G., \& Sari, W. P. (2019). Bentuk Komunikasi Pemasaran Digital ST22 Consulting. Prologia, 2(2), 339-346. https://doi.org/10.24912/pr.v2i2.3598 
Rachman, R., \& Abadi, T. W. (2017). Komunikasi Word Of Mouth dan Keputusan Pembelian Batik Bangkalan | Rachman | Jurnal ASPIKOM. Jurnal ASPIKOM, 3(2), 285-295. https://jurnalaspikom.org/index.php/aspikom/article/view/136

Rajagopal. (2011). Consumer culture and purchase intentions toward fashion apparel in Mexico. Journal of Database Marketing and Customer Strategy Management, 18(4), 286-307. https://doi.org/10.1057/dbm.2011.33

Ross, J., \& Harradine, R. (2004). I'm not wearing that! Branding and young children. Journal of Fashion Marketing and Management, 8(1), 11-26. https://doi.org/10.1108/13612020410518664

Rossiter, J. R. (2014). "Branding" explained: Defining and measuring brand awareness and brand attitude. In Journal of Brand Management (Vol. 21, Issue 7, pp. 533-540). Palgrave Macmillan Ltd. https://doi.org/10.1057/bm.2014.33

Santoso, W. M., Kemasyarakatan, P., \& Kebudayaan, D. (2015). Komodifikasi Mode Muslimah Melalui Media Sosial . Jurnal Masyarakat \& Budaya, 17(3), 299-316. https://doi.org/10.14203/JMB.V17I3.321

Schivinski, B., \& Dabrowski, D. (2013). The impact of brand communication on brand equity through Facebook. In GUT FME Working Paper Series A. Emerald Group Publishing Ltd. https://ideas.repec.org/p/gdk/wpaper/4.html

Semuel, H., \& Setiawan, K. Y. (2018). Promosi Melalui Sosial Media, Brand Awareness, Purchase Intention Pada Produk Sepatu Olahraga. Jurnal Manajemen Pemasaran, 12(1), 47-52. https://doi.org/10.9744/PEMASARAN.12.1.47-52

Sugiyono. (2013). metodologi penelitian kuantitatif kualitatif dan R \& D. In Bandung: Alfabeta. https://doi.org/10.1164/rccm.200409-1267OC

Sukarwo, W. (2017). Krisis Identitas Budaya: Studi Poskolonial pada Produk Desain Kontemporer. Jurnal Desain, 4(03), 311-324. https://doi.org/10.30998/jurnaldesain.v4i03.1869

Syafaruddin, K., \& Mahfiroh, N. (2020). Komodifikasi Nilai Islam Dalam Fashion Muslim Di Instagram. Profetika: Jurnal Studi Islam, 21(1), 8-16. https://doi.org/https://doi.org/10.23917/profetika.v21i1.11644

Tunjungsari, H. K., Selamat, F., \& Chairy, C. (2019). Pengukuran Destination Awareness Wisatawan Domestik pada Candi Muaro Jambi. Jurnal Komunikasi, 11(2), 233-247. https://doi.org/10.24912/jk.v11i2.5796

Valaei, N., \& Nikhashemi, S. R. (2017). Generation Y consumers' buying behaviour in fashion apparel industry: a moderation analysis. Journal of Fashion Marketing and Management, 21(4), 523-543. https://doi.org/10.1108/JFMM-01-2017-0002

Velasquez, A., \& LaRose, R. (2015). Social Media for Social Change: Social Media Political Efficacy and Activism in Student Activist Groups. Journal of Broadcasting and Electronic Media, 59(3), 456-474. https://doi.org/10.1080/08838151.2015.1054998

Wang, X. (2011). The Effect of Inconsistent Word-of-Mouth During The Service Encounter. Journal of Services Marketing, 25(4), 252-259. https://doi.org/10.1108/08876041111143087 
Yaseen, S., \& Mazahir, I. (2019). Impact of Corporate Credibility, Brand Awareness, Brand Image and Brand Loyalty on Purchase Intention in the Telecommunication Sector of Karachi. Global Management Journal for Academic \& Corporate Studies, 9(1). https://gmjacs.bahria.edu.pk/wpcontent/uploads/2019/07/Paper-8.pdf

Yusop, F. D., \& Sumari, M. (2013). The Use of Social Media Technologies among Malaysian Youth. Procedia - Social and Behavioral Sciences, 103, 12041209. https://doi.org/10.1016/j.sbspro.2013.10.448 